\title{
BMJ Open Multicentre cohort study of cochlear implantation outcomes in Thailand
}

\author{
Patorn Piromchai (D) , ${ }^{1,2}$ Napas Tanamai, ${ }^{3}$ Sivaporn Kiatthanabumrung, ${ }^{4}$ \\ Suwicha Kaewsiri, ${ }^{5}$ Kanthong Thongyai, ${ }^{6}$ Viraporn Atchariyasathian, ${ }^{7}$ \\ Panida Thanawirattananit, ${ }^{1,2}$ Chitsuda Wacharasindhu, ${ }^{8}$ Tulakan Mukkun, ${ }^{9}$ \\ Permsarp Isipradit, ${ }^{10}$ Kwanchanok Yimtae $^{1,2}$
}

To cite: Piromchai P, Tanamai N, Kiatthanabumrung S, et al. Multicentre cohort study of cochlear implantation outcomes in Thailand. BMJ Open 2021;11:e054041. doi:10.1136/ bmjopen-2021-054041

- Prepublication history for this paper is available online. To view these files, please visit the journal online (http://dx.doi. org/10.1136/bmjopen-2021054041).

Received 01 June 2021 Accepted 08 November 2021

Check for updates

(C) Author(s) (or their employer(s)) 2021. Re-use permitted under CC BY-NC. No commercial re-use. See rights and permissions. Published by BMJ.

For numbered affiliations see end of article.

Correspondence to Dr Kwanchanok Yimtae; kwayim@kku.ac.th

\section{ABSTRACT}

Objectives To report the status and outcomes of cochlear implantation in Thailand.

Design Cohort study.

Setting Tertiary care and university hospitals.

Participants Patients who underwent cochlear implant surgery in Thailand.

Interventions This project collected data from all government and university hospitals in Thailand where cochlear implant surgery was performed between 2016 and 2020.

Primary and secondary outcome measures Baseline characteristics, operation data, complications, audiological outcomes and quality of life were reported.

Results This study included 458 patients, and nearly half of the patients were children and adolescents (46.94\%).

The mean age of the patients was $2.96 \pm 5.83$ years. At 1 year postoperatively, the mean pure tone average of the hearing threshold in the implanted ear significantly improved from unaided preoperative baseline (mean difference (MD) $64.23 \mathrm{~dB} \mathrm{HL}$; $95 \%$ Cl 59.81 to 68.65 ; $\mathrm{p}<0.001)$. The mean speech recognition threshold also improved (MD 55.96 dB HL; $95 \% \mathrm{Cl} 49.50$ to 62.42 , $p<0.001)$. The quality-of-life scores of the $E Q-5 D-5 L$, PedsQL and HUI3 questionnaires at 1 year showed improved mobility (range, $0-5$; MD $0.65 ; 95 \% \mathrm{Cl} 0.05$ to $1.25 ; p=0.037$ ), hearing (range, $0-6 ; \mathrm{MD} 0.96 ; 95 \% \mathrm{Cl}$ 0.30 to $1.61 ; p=0.006$ ) and speech (range, $0-5$; MD 0.44; $95 \% \mathrm{Cl} 0.04$ to $0.84 ; p=0.031)$. Common complications included electrode dislodgement $(2.18 \%)$, vertigo (1.23\%) and meningitis (1.93\%).

Conclusions Excellent audiological outcomes and improvement in the quality of life in the mobility, hearing and speech domains were observed in patients who underwent cochlear implantation in Thailand.

\section{INTRODUCTION}

Hearing impairment is a major disability that can affect the quality of life. ${ }^{1-3}$ According to the Department of Empowerment of Persons with Disabilities, 375680 hearing-impaired patients were registered with the government in Thailand in 2018.

Cochlear implant devices can help patients with severe to profound sensorineural hearing loss to regain hearing. Speech perception,

\section{Strengths and limitations of this study}

This is a multicentre prospective cohort study to collect the cochlear implantation outcomes conducted in Thailand.

- This study collected data from 2016 to 2020.

- We did not collect data from private hospitals, and some data were missing due to the nature of the cohort study.

quality of life and neurocognitive function improve after cochlear implantation. ${ }^{5-7}$

In Thailand, cochlear implant surgery was first performed in 1986 using a 3M device from the USA. Gradually, university hospitals and major tertiary hospitals started to perform this surgery. However, the number of patients who underwent this procedure was modest owing to the price of the devices, and it was not supported by the universal health scheme.

Only a few single-institution studies have assessed the efficacy of this technology in Thailand. ${ }^{8}$ No conclusive evidence of the benefits of cochlear implant devices in the Thai population is available and data from Western countries may not be applicable in low-income and middle-income countries. The Thai government needs more local evidence to establish a cochlear implant device as a basic medical benefit for all Thai people.

This nationwide project with support from the Health Systems Research Institute of Thailand was initiated to prospectively collect cochlear implantation outcomes in the Thai population to provide recommendations to the government on cochlear implantation policy. ${ }^{10}$

This study aimed to evaluate the efficacy of cochlear implantation in terms of audiological outcomes and quality of life in the Thai population. 
Table 1 Demographic data

\begin{tabular}{|c|c|c|}
\hline & $\mathrm{N}=458$ & $\%$ \\
\hline \multicolumn{3}{|l|}{ Sex } \\
\hline Male & 220 & 48.03 \\
\hline Female & 203 & 44.32 \\
\hline No data & 35 & 7.64 \\
\hline \multicolumn{3}{|l|}{ Age } \\
\hline Infants and toddlers (<4 years) & 44 & 9.61 \\
\hline Preschool children (4-7 years) & 79 & 17.25 \\
\hline Early school children (8-12 years) & 52 & 11.35 \\
\hline Adolescents (13-18 years) & 40 & 8.73 \\
\hline Adults (>18 years) & 211 & 46.07 \\
\hline No data & 32 & 6.99 \\
\hline \multicolumn{3}{|l|}{ The onset of hearing loss } \\
\hline Prelingual hearing loss & 210 & 45.85 \\
\hline Postlingual hearing loss & 152 & 33.19 \\
\hline No data & 96 & 20.96 \\
\hline
\end{tabular}

Type of deafness

\begin{tabular}{lcc}
\hline Bilateral deafness & 458 & 100 \\
\hline Unilateral deafness & 0 & 0 \\
\hline Causes of hearing loss & & \\
Congenital & $\mathrm{N}=241$ & \\
\hline Idiopathic & 125 & 51.87 \\
\hline Inner ear anomalies & 12 & 4.98 \\
\hline Genetic disorder & 7 & 2.90 \\
\hline Intrauterine infection & 5 & 2.07 \\
\hline Birth asphyxia & 4 & 1.66 \\
\hline Ototoxicity & 1 & 0.41 \\
\hline Others & 5 & 2.07 \\
\hline No data & 82 & 34.02 \\
\hline Acquired & $\mathrm{N}=181$ & \\
\hline Idiopathic & 67 & 37.02 \\
\hline Post meningitis & 63 & 34.81 \\
\hline Chronic otitis media or cholesteatoma & 10 & 5.52 \\
\hline Sepsis & 4 & 2.21 \\
\hline Ototoxicity & 3 & 1.66 \\
\hline Trauma & 3 & 1.66 \\
\hline Head injury & 3 & 1.66 \\
\hline Noise-induced or noise trauma & 2 & 1.10 \\
\hline Autoimmune hearing loss & 19 & 0.55 \\
\hline Others & 6.50 \\
\hline No data & & 3.31 \\
\hline & & \\
\hline & 3 & \\
\hline & & \\
\hline
\end{tabular}

\section{METHODS}

\section{Study design and setting}

All government and university hospitals in Thailand that were equipped to perform cochlear implant surgery were involved. A total of eight university hospitals (Srinagrind
Hospital, King Chulalongkorn Memorial Hospital, Ramathibodi Hospital, Songklanagarind Hospital, Siriraj Hospital, Maharaj Nakorn Chiangmai Hospital, Phramongkutklao Hospital and HRH Princess Maha Chakri Sirindhorn Medical Center) and three tertiary hospitals (King Bhumibol Adulyadej Hospital, Rajavithi Hospital and Trang Hospital) participated in this study. These were the major hospitals that performed cochlear implant surgery in Thailand.

\section{Participants}

We included all patients who underwent cochlear implantation at a network hospital between July 2016 and April 2020. There were no exclusion criteria.

\section{Outcomes}

We collected baseline characteristics, operation data, complications, auditory performance and quality of life data.

The baseline characteristics and operation data included the age, sex, onset of hearing loss, type of deafness, cause of hearing loss, IQ using Wechsler Intelligence Scales ${ }^{11}$ and mental health status evaluated by psychologists (normal or abnormal), type of hospital, electrode insertion depth and insertion technique.

\section{Auditory performance outcomes}

Auditory performance was assessed based on pure tone audiometry, speech recognition threshold (SRT), speech discrimination core (SDS) and categories of auditory performance scores (CAP).

Pure tone audiometry was performed to determine air-conduction hearing thresholds. Thresholds were tested separately for each ear, octave-by-octave, from 250 to $8000 \mathrm{~Hz}$. A pure tone average (PTA) refers to the average of hearing threshold levels at 500, 1000, 2000 and $4000 \mathrm{~Hz}^{12}$

The SRT is the minimum hearing level for speech at which an individual can recognise $50 \%$ of the speech material. A recognition task is one in which the participant selects the test item from a closed set of choices. The individual should repeat or, in some other manner, indicate recognition of the speech material $50 \%$ of the time. ${ }^{13}$ In this study, the original Thai monosyllabic word lists (RAMA.SD-1) containing five lists of 25 monosyllabic words were used. ${ }^{14}$

The SDS was a score of the number of words correctly repeated from phonetically balanced word lists, expressed as a percentage of correct. ${ }^{15}$

The CAP scale is a functional performance evaluation that was developed as part of the Nottingham Cochlear Implant Programme and as a global assessment of auditory receptive abilities. It is a nonlinear scale on which patients' developing auditory abilities can be rated in eight categories of increasing difficulty from 0 to 7 ( 0 : no awareness of environmental sounds; (1) awareness of environmental sounds; (2) response to speech sounds; (3) identification of environmental sounds; (4) discrimination of some 


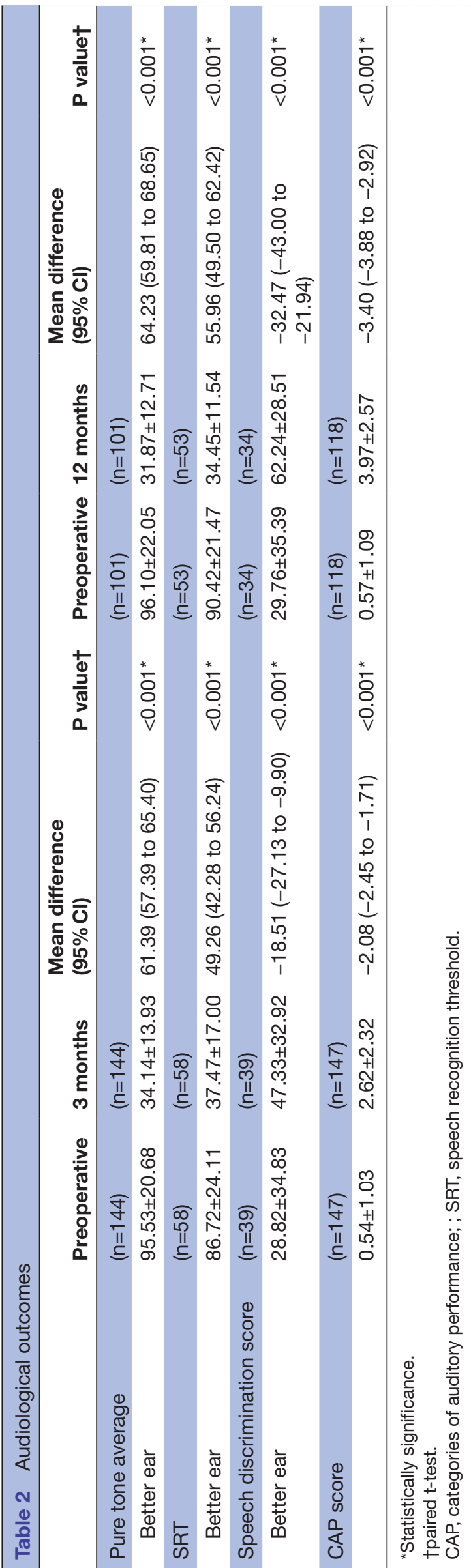

speech sounds without lip-reading; (5) understanding common phrases without lip-reading; (6) understanding conversation without lip-reading and (7) using the telephone with a known speaker). ${ }^{16} 17$

All auditory performance outcomes were collected at baseline (preoperative) and at 3 and 12 months postoperatively. The preoperative auditory performance was unaided assessment (without hearing aids) while postoperative evaluation was aided assessment (cochlear implant device turn on).

Quality of life outcomes

Quality of life was evaluated using EQ-5D-5L (for patients older than 18 years of age), ${ }^{18}$ the Paediatric Quality of Life Inventory-PedsQL (for patients between 2 and 18 years), ${ }^{19}$ and the health utilities index mark 3-HUI3 (for patients older than 8 years of age) ${ }^{20}$

The EQ-5D-5L (the EuroQol Research Foundation 5-level EQ-5D version) is a general health status questionnaire with a descriptive system and a Visual Analogue Scale (VAS). The descriptive system comprises five dimensions: mobility, self-care, usual activities, pain/discomfort and anxiety/depression. Each dimension has five levels: no problems, slight problems, moderate problems, severe problems and extreme problems. The patient is asked to indicate their health state by ticking the box next to the most appropriate statement in each of the five dimensions. The VAS records the patient's self-rated health on a vertical VAS, where the endpoints are labelled 'The best health you can imagine' and 'The worst health you can imagine'. The VAS can be used as a quantitative measure of health outcomes that reflect the patient's own judgement. $^{18}$

The PedsQL (Pediatric Quality of Life Inventory ${ }^{\mathrm{TM}}$ ) is a general health status questionnaire for children and adolescents. This questionnaire evaluates the four dimensions delineated by WHO, which are: physical, emotional, social and school functioning. Each item has five levels: never, almost never, sometimes, often and almost always. The scores ranged from 0 to $100 .^{21}$

HUI3 (Health Utility Index Mark 3) is a generic healthrelated quality of life for measuring health status, healthrelated quality of life and utility scores. Health dimensions include vision, hearing, speech, ambulation/mobility, pain, dexterity, self-care, emotion and cognition. Each dimension has 5-6 levels. ${ }^{22}$

Quality of life data were collected at 1, 3 and 12 months postoperatively. In children aged less than 5 years old, the input on the quality of life was derived from their parents or caregivers.

\section{Definitions}

Deafness was defined as PTA (from four frequencies 0.5, 1,2 and $4 \mathrm{kHz}$ ) or SRT $>80 \mathrm{~dB} \mathrm{HL}$ according to the WHO classification or no response to an auditory brainstem response at the maximum intensity of $90 \mathrm{~dB} \mathrm{HL}^{23}$

Implantation success was defined as a PTA or SRT $\leq 50 \mathrm{~dB}$ and SDS $\geq 50 \%$ (category B) within 1 year postoperatively 


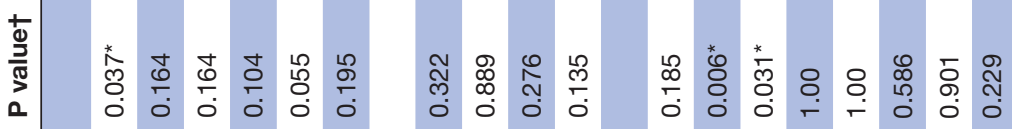

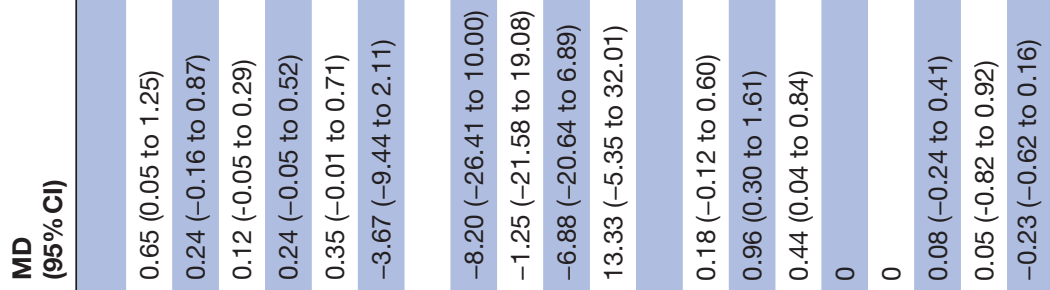

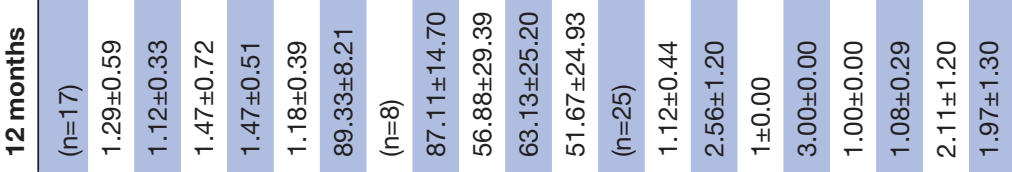

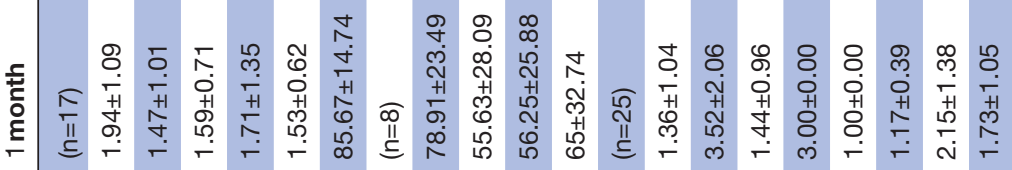

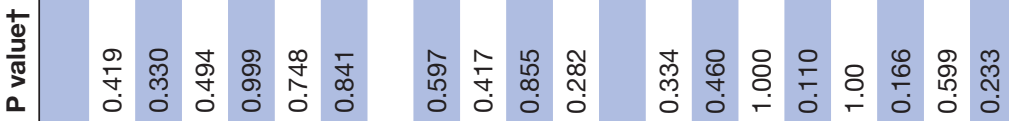

ํํํ ㅇํㅇ

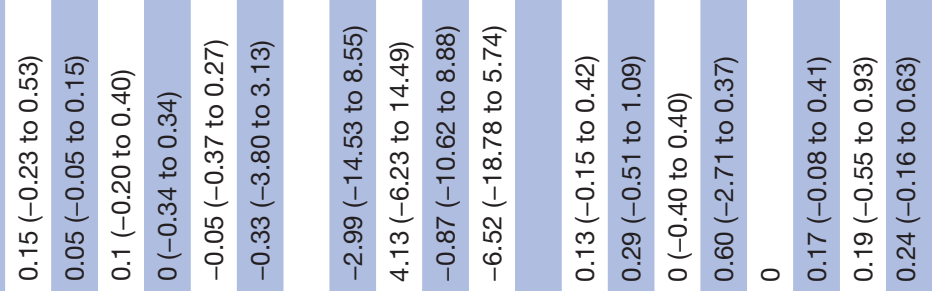
D)

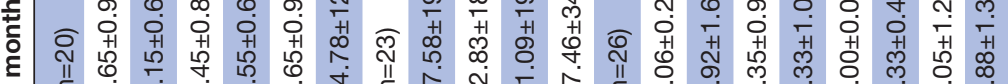

至

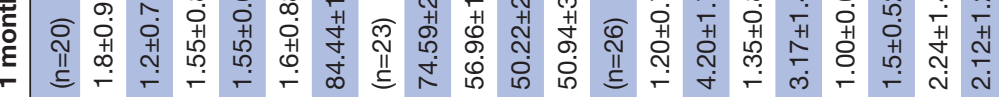

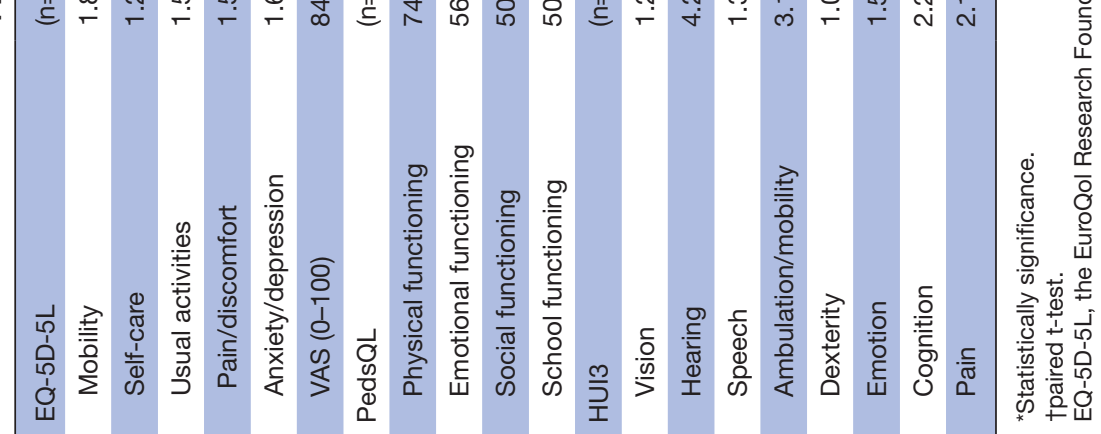


Table 4 The factors contributing to the success of the implantation

\begin{tabular}{|c|c|c|c|c|}
\hline Factors & N/per cent success in 1 year & OR & $95 \% \mathrm{Cl}$ & $P$ value \\
\hline \multicolumn{5}{|l|}{ Age } \\
\hline Infants and toddlers ( $<4$ years) $(n=9)$ & $8(88.89)$ & 1 & & \\
\hline Early school children (8-12 years) $(n=27)$ & $23(85.19)$ & 0.72 & 0.07 to 7.42 & 0.782 \\
\hline Adolescents (13-18 years) $(n=23)$ & $22(95.65)$ & 2.75 & 0.15 to 49.36 & 0.492 \\
\hline \multicolumn{5}{|l|}{ Sex } \\
\hline Male $(n=119)$ & $103(86.55)$ & 1 & & \\
\hline Female $(n=107)$ & $89(83.18)$ & 0.77 & 0.37 to 1.59 & 0.479 \\
\hline \multicolumn{5}{|l|}{ Onset of hearing loss } \\
\hline Prelingual hearing loss $(n=112)$ & $98(87.50)$ & 1 & & \\
\hline Oral $(n=122)$ & $108(88.52)$ & 1 & & \\
\hline Sign language $(n=21)$ & $18(85.71)$ & 0.78 & 0.20 to 2.98 & 0.714 \\
\hline Combined $(n=77)$ & $61(79.22)$ & 0.49 & 0.23 to 1.08 & 0.078 \\
\hline \multicolumn{5}{|l|}{ Aetiology } \\
\hline Congenital $(n=112)$ & $98(87.50)$ & 1 & & \\
\hline Acquired $(n=115)$ & $95(82.61)$ & 0.68 & 0.32 to 1.42 & 0.304 \\
\hline \multicolumn{5}{|l|}{ IQ } \\
\hline Above low Average $(n=62)$ & $51(82.26)$ & 1 & & \\
\hline Borderline or extremely low $(n=36)$ & $33(91.67)$ & 2.37 & 0.62 to 9.15 & 0.210 \\
\hline \multicolumn{5}{|l|}{ Electrode insertion } \\
\hline Full $(n=214)$ & $183(85.51)$ & 1 & & \\
\hline Partial $(n=15)$ & $11(73.33)$ & 0.47 & 0.14 to 1.56 & 0.214 \\
\hline \multicolumn{5}{|l|}{ Insertion technique } \\
\hline Cochleostomy (n=158) & $130(82.28)$ & 1 & & \\
\hline Round window $(n=69)$ & $62(89.86)$ & 1.91 & 0.79 to 4.61 & 0.151 \\
\hline
\end{tabular}

according to the American Academy of OtolaryngologyHead and Neck Surgery classification. ${ }^{24}$

\section{Patient and public involvement}

The Health Systems Research Institute of Thailand is a public body financed by the government of Thailand, which has a role in protocol development. Representatives from the National Association of the Deaf in Thailand also provided input for this study.

\section{Statistical analysis}

Statistical analyses were performed using IBM SPSS V.20 and Stata V.14. Data were described as either means (for continuous variables) or frequencies and percentages (for categorical variables). Significant differences between groups were determined using the Student's t-test, paired sample t-test, or Mann-Whitney U test for continuous variables. The $\chi^{2}$ test or Fisher's exact test was used to determine whether there was a significant difference between the expected and observed frequencies. The factor of success is presented as an OR. For all tests, statistical significance was set at $\mathrm{p}<0.05$. 


\begin{tabular}{lcc}
\hline Table 5 Complications & & \\
\hline Immediate complications & $\mathbf{N}=\mathbf{4 0 7}$ & $\%$ \\
\hline Vertigo & 5 & 1.23 \\
Facial weakness & 3 & 0.74 \\
Electrodes dislodge & 1 & 0.25 \\
Tinnitus & 0 & 0 \\
Wound infection & 0 & 0 \\
Bleeding & 0 & 0 \\
Others & 12 & 2.95 \\
Delayed complications & $\mathrm{N}=465$ & $\%$ \\
Meningitis & 9 & 1.93 \\
Electrodes dislodge & 9 & 1.93 \\
Implant migration/extrusion & 8 & 1.72 \\
Device failure & 7 & 1.51 \\
Others & 19 & 4.09 \\
\hline
\end{tabular}

\section{RESULTS}

\section{Patient's demographics}

There were 458 patients in this study, of whom, 220 were male and 203 were female. Nearly half of the patients were children and adolescents (46.94\%). The common causes of congenital and acquired hearing disabilities were idiopathic (51.87\% and $34.02 \%$, respectively) (table 1 ).

\section{Audiological outcomes}

Preoperatively, the mean PTA, mean SRT, mean SDS and mean CAP score was 95.53 dB HL, 86.72 dB HL, 28.82\% and 0.54 points, respectively. At 3 months postoperatively, the mean PTA, mean SRT, mean SDS and mean CAP score was $34.14 \mathrm{~dB} \mathrm{HL}, 37.47 \mathrm{~dB} \mathrm{HL}, 47.33 \%$ and 2.62 points, respectively. At 12 months postoperatively, the mean PTA, mean SRT, mean SDS and mean CAP score was $31.87 \mathrm{~dB}$ HL, $34.45 \mathrm{~dB}$ HL, $62.24 \%$ and 3.97 points, respectively.

All audiological outcomes were significantly improved from baseline at 3 months $(\mathrm{p}<0.001)$ and 12 months postoperation $(\mathrm{p}<0.001)$ (table 2$)$.

\section{Quality of life outcomes}

For EQ-5D-5L, the mean score for the mobility domain (range, 0-5; lower is better) significantly improved at 12 months compared with the postoperative first month (mean difference, MD, $0.65 ; 95 \%$ CI 0.05 to 1.25 ; $\mathrm{p}=0.037)$. However, there were no statistically significant differences in the other domains $(\mathrm{p}>0.05)$.

For PedsQL (range, 0-100; higher is better), there was no statistically significant difference in physical, emotional, social and school functioning domains at 3 and 12 months compared with the postoperative first month $(\mathrm{p}>0.05)$.

For HUI3, the mean score for hearing (range, 0-6; lower is better) and speech domain (range, 0-5; lower is better) significantly improved at 12 months compared with the postoperative first month (MD for hearing score, 0.96 points; $95 \%$ CI 0.30 to 1.61 ; $\mathrm{p}=0.006$; MD for

speech score, 0.44 points; $95 \%$ CI 0.04 to $0.84 ; \mathrm{p}=0.031$ ). However, there were no statistically significant differences in the other domains $(\mathrm{p}>0.05)$ (table 3$)$.

\section{Factors contributing to the success}

The effect of factors including the age, sex, onset of hearing loss, type of communication, aetiology, IQ mental health status, type of hospital, electrode insertion and insertion technique on the success of cochlear implantation was evaluated. However, there were no significant differences in the odds of success between factors $(p>0.05)$ (table 4).

\section{Complications}

The most common immediate postoperative complications were vertigo, facial weakness and electrode dislodgement. Most common delayed complications included meningitis, electrode dislodgement and cochlear implant migration/extrusion (table 5).

\section{DISCUSSION}

Cochlear implants can help patients with severe or profound sensorineural hearing loss to regain hearing. This results in a better quality of life in adults and ultimately helps in the linguistic and social developmental processes in children. ${ }^{25}$ However, most data on patient outcomes have been collected in individual institutions, which makes it less generalisable.

Several studies have found that speech perception and disease-specific quality of life scores were significantly improved in adults. ${ }^{6}{ }^{26}$ A recent systematic review of 18 articles, including a total of 1093 records of older adults who underwent cochlear implantation, found that an improvement in disease-specific quality of life was generally reported. However, the generic quality of life questionnaires assessing general health status were ambiguous. The author concluded that there is a need for a standardised quality of life assessment tool for patients with cochlear implantation. ${ }^{27}$

There are no standard cochlear implantation criteria in Thailand. The common criteria used in most institutes were:

1. Deafness was defined as PTA (from four frequencies $0.5,1,2$ and $4 \mathrm{kHz}$ ) or SRT $>80 \mathrm{~dB}$ HL according to the WHO classification or no response to an auditory brainstem response at the maximum intensity of $90 \mathrm{~dB}$ HL.

2. No or little benefit from hearing aids.

3. SDS $<50 \%$.

4. The onset of deafness should not be $>10$ years.

Our previous study collected data from 226 patients with cochlear implantation. We found that the audiological outcomes, including PTA, SRT and SDS, were significantly improved compared with the preoperative period $(\mathrm{p}=0.001, \mathrm{p}<0.001$ and $\mathrm{p}<0.001$, respectively). However, the quality of life data did not significantly improve. ${ }^{28}$ 
To the best of our knowledge, this is the first project with government support to evaluate the outcomes of cochlear implantation at the national level. We prospectively collected data from patients who underwent cochlear implant surgery in Thailand.

In this study, we found that audiological outcomes, including PTA, SRT and SDS, were significantly improved $(p<0.001, p<0.001$ and $p<0.001$, respectively). The quality of life, including mobility, hearing and speech domains, was significantly improved $(\mathrm{p}=0.037, \mathrm{p}=0.006$, and $\mathrm{p}=0.031$, respectively).

We also tried to identify factors leading to the success of cochlear implantation in our setting; however, no factor significantly impacted the success $(p>0.05)$.

This study had limitations owing to the nature of the cohort study. Approximately $10 \%$ of data were missing for most variables. This study was designed to follow up patients for 5 years. However, the number of patients reporting for follow-up after 1 year declined sharply. Therefore, we limited the analysis of outcomes to 1 year after cochlear implantation.

The results of this study showed the excellent audiological outcomes and improvement of the quality of life in mobility, hearing, and speech domains in patients who underwent cochlear implantation in Thailand. Future studies should investigate the long-term hearing outcomes using standardised quality of life questionnaire for patients with cochlear implantation.

\section{CONCLUSION}

Excellent audiological outcomes and improvement in the quality of life in the mobility, hearing and speech domains were observed in patients who underwent cochlear implantation in Thailand.

\section{Author affiliations}

${ }^{1}$ Department of Otorhinolaryngology, Faculty of Medicine, Khon Kaen University, Khon Kaen, Thailand

${ }^{2}$ Khon Kaen Ear, Hearing and Balance Research Group, Khon Kaen University, Khon Kaen, Thailand

${ }^{3}$ Center of Excellence in Otolaryngology, Head \& Neck Surgery, Rajavithi Hospital, Bangkok, Thailand

${ }^{4}$ Department of Otolaryngology, Faculty of Medicine, Ramathibodi Hospital, Mahidol University, Bangkok, Thailand

${ }^{5}$ Department of Otolaryngology, Faculty of Medicine, Chiang Mai University, Chiang Mai, Thailand

${ }^{6}$ Department of Otolaryngology, Faculty of Medicine, Siriraj Hospital, Mahidol University, Bangkok, Thailand

${ }^{7}$ Department of Otolaryngology, Faculty of Medicine, Prince of Songkla University, Songkla, Thailand

${ }^{8}$ Department of Otolaryngology, Bhumibol Adulyadej Hospital, Bangkok, Thailand

${ }^{9}$ Department of Otolaryngology, Trang Hospital, Trang, Thailand

${ }^{10}$ Department of Otolaryngology, Faculty of Medicine, Chulalongkorn University,

Bangkok, Thailand

Acknowledgements The authors would like to thank the patients who participated in this trial, the staff at the participating hospitals for their assistance, and the Khon Kaen Ear, Hearing and Balance Research Group for their support.

Contributors PP conceptualised, designed and supervised the study, performed data analysis, interpreted the results, drafted the manuscript, and responsible for the overall content as guarantor. NT, SKi, SKa, KT, VA, PT, CW, TM and PI contributed to data collection. KY contributed to the study design, data collection, supervision of the study. and and responsible for the overall content as guarantor. All authors contributed to the interpretation and discussion of the results and read and approved the final manuscript.

Funding This work was supported by the Health Systems Research Institute of Thailand (Grant ID: 61-070) and internal support by the Faculty of Medicine, Khon Kaen University, Thailand (Grant ID: AS64207).

Competing interests None declared.

Patient and public involvement Patients and/or the public were involved in the design, or conduct, or reporting, or dissemination plans of this research. Refer to the Methods section for further details.

Patient consent for publication Not applicable.

Ethics approval This study was approved by the Central Research Ethics Committee of Thailand (CERT004/59BRm). Written informed consent to participate in this study was provided by all patients enrolled.

Provenance and peer review Not commissioned; externally peer reviewed.

Data availability statement Data are available on reasonable request. Individual deidentified data will be available on reasonable request. Extra data are available by emailing kwayim@kku.ac.th.

Open access This is an open access article distributed in accordance with the Creative Commons Attribution Non Commercial (CC BY-NC 4.0) license, which permits others to distribute, remix, adapt, build upon this work non-commercially, and license their derivative works on different terms, provided the original work is properly cited, appropriate credit is given, any changes made indicated, and the use is non-commercial. See: http://creativecommons.org/licenses/by-nc/4.0/.

ORCID iD

Patorn Piromchai http://orcid.org/0000-0002-2195-4837

\section{REFERENCES}

1 Piromchai P, Kasemsiri P, Vatanasapt P, et al. Ear, nose, throat and craniofacial diseases community services initiative of Khon Kaen university. J Med Assoc Thai 2016;99:S81-5.

2 Piromchai P, Laohasiriwong S, Saesiew P. Ear, nose, throat, and craniofacial disease screening in primary school: Khon Kaen university 2017 initiative. J Med Assoc Thai 2018;101:77.

3 Piromchai P, Saeseow P, Reechaipichitkul W. Prevalence of Ear, Nose, and Throat Diseases in the Elderly: Khon Kaen University's Community Service from 2017 to 2018. J Med Assoc Thai 2019;102:128.

4 Department of Empowerment of Persons with Disabilities of Thailand. Report of persons with disabilities. Bangkok: Department of Empowerment of Persons with Disabilities of Thailand, 2018.

5 Crowson MG, Semenov YR, Tucci DL, et al. Quality of life and cost-effectiveness of cochlear implants: a narrative review. Audiol Neurootol 2017;22:236-58.

6 Völter C, Götze L, Haubitz I, et al. Benefits of cochlear implantation in middle-aged and older adults. Clin Interv Aging 2020;15:1555-68.

7 Völter C, Götze L, Haubitz I, et al. Impact of cochlear implantation on neurocognitive subdomains in adult cochlear implant recipients. Audiol Neurootol 2021;26:236-45.

8 Vaewvichit K, Luangpitakchumpol P. Cochlear implantation in Thailand. J Laryngol Otol 1999;113:515-7.

9 Kasemsuwan L, Cheewaruangroj W, Tungkeeratichai J, et al. Audiological outcomes of cochlear implantation in Ramathibodi Hospital. J Med Assoc Thai 2011;94:1380-6.

10 Piromchai P. Cochlear implantation. Bangkok: Health Systems Research Institute of Thailand (HSRI), 2020.

11 Flanagan DP, McGrew KS, Ortiz SO. The Wechsler intelligence scales and Gf-Gc theory: a contemporary approach to interpretation. Allyn \& Bacon, 2000.

12 Favier V, Vincent C, Bizaguet É, et al. French Society of ENT (SFORL) guidelines (short version): audiometry in adults and children. Eur Ann Otorhinolaryngol Head Neck Dis 2018;135:341-7.

13 American Speech-Language-Hearing Association. Determining threshold level for speech [Guidelines]. Available: www.asha.org/ policy

14 Amatayakul P. Introduction to audiology (hearing sciences): Mahidol University, Bangkok, Thailand 1968.

15 Boothroyd A. Statistical theory of the speech discrimination score. $J$ Acoust Soc Am 1968;43:362-7. 
16 Archbold S, Lutman ME, Marshall DH. Categories of auditory performance. Ann Otol Rhinol Laryngol Suppl 1995;166:312-4.

17 Thawin C, Kanchanalarp C, Lertsukprasert K, et al. Auditory performance of cochlear implant children aged 2-5 years. $J$ Med Assoc Thai 2006;89:1923-7.

18 Herdman M, Gudex C, Lloyd A, et al. Development and preliminary testing of the new five-level version of EQ-5D (EQ-5D-5L). Qual Life Res 2011;20:1727-36.

19 Varni JW, Seid M, Rode CA. The PedsQL: measurement model for the pediatric quality of life inventory. Med Care 1999;37:126-39.

20 Furlong W, Feeny D, Torrance G. Multiplicative multi-attribute utility function for the health Utilities index mark $3(\mathrm{HUI} 3)$ system: a technical report: centre for health economics and policy analysis (CHEPA), McMaster University 1998.

21 Varni JW, Burwinkle TM, Seid M, et al. The PedsQL 4.0 as a pediatric population health measure: feasibility, reliability, and validity. Ambul Pediatr 2003;3:329-41.

22 Grutters JPC, Joore MA, van der Horst F, et al. Choosing between measures: comparison of EQ-5D, HUI2 and HUI3 in persons with hearing complaints. Qual Life Res 2007;16:1439-49.
23 Olusanya BO, Davis AC, Hoffman HJ. Hearing loss grades and the International classification of functioning, disability and health. Bull World Health Organ 2019;97:725-8.

24 Carlson ML, Vivas EX, McCracken DJ, et al. Congress of neurological surgeons systematic review and evidence-based guidelines on hearing preservation outcomes in patients with sporadic vestibular schwannomas. Neurosurgery 2018;82:E35-9.

25 Ruben RJ. Language development in the pediatric cochlear implant patient. Laryngoscope Investig Otolaryngol 2018;3:209-13.

26 Olze H, Knopke S, Gräbel S, et al. Rapid positive influence of cochlear implantation on the quality of life in adults 70 years and older. Audiol Neurootol 2016;21:43-7.

27 Andries E, Gilles A, Topsakal V, et al. Systematic review of quality of life assessments after cochlear implantation in older adults. Audiol Neurootol 2021;26:61-75.

28 Kasemsiri P, Thanawirattananit P, Yimtae K. The outcomes of cochlear implantation in Thailand: audiologic performance and quality of life. J Med Assoc Thai 2018;101:203. 